\title{
Parameters affecting oleochemical production from waste bleaching earth via alcoholysis
}

\author{
ÖMER FARUK GÜL*, MELEK TUTER and FILIZ KARAOSMANOGLU \\ Department of Chemical Engineering, Istanbul Technical University, Maslak, Istanbul, Turkey \\ e-mail: gulomerfaruk@yahoo.com; tuter@itu.edu.tr; filiz@itu.edu.tr
}

MS received 25 August 2016; revised 12 February 2017; accepted 3 March 2017; published online 23 October 2018

\begin{abstract}
The edible oil industry is one of the largest industries in the world. In the edible oil refining process, large amounts of waste are discarded every day. Evaluation of these wastes is vital for environmental issues. Most of this waste is due to the bleaching process in which bleaching earths are largely used. Due to its high adsorption capacity, bleaching earth adsorbs oil nearly $40 \%$ of its weight. In order to evaluate this waste for oleochemical production, alcoholysis reactions were investigated. Parameters affecting the reaction, such as catalyst type and amount, alcohol type, alcohol:oil molar ratio and temperature, were investigated. The reactions were conducted in the presence of different catalysts such as $\mathrm{NaOH}, \mathrm{NaOCH}_{3}$ and homogeneous alkali polymeric gel catalyst (HAPJEK) and performed at a temperature range of $60-78^{\circ} \mathrm{C}$ and in the presence of a catalyst (1-2\% based on oil weight) at alcohol:oil molar ratios of 5:1-7:1. Based on optimisation by response surface methodology (RSM), the critical synthesis conditions for 210 min reaction time with a maximum of $85.8 \%$ methyl ester content were determined as temperature: $68.4^{\circ} \mathrm{C}$, catalyst amount $1.5 \%$ based on oil weight and methanol/oil molar ratio: 6.4 .
\end{abstract}

Keywords. Waste bleaching earth; oleochemicals; fatty acid ester; response surface methodology; biodiesel.

\section{Introduction}

Energy consumption and waste production always occur all around the world, so it must be properly organised and managed. In recent years, due to increasing numbers of legislations on environment, waste treatment and disposal have become significant. For this reason, biomass and biodegradable part of municipal and industrial wastes should be evaluated as beneficial product via thermochemical and biochemical conversion processes [1].

Solid wastes from vegetable oil refining industry have turned out to be an important source for producing organic compounds. Bleaching earth is one of the most commonly used adsorbents due to its high adsorption capacity [2, 3]. However, only a small amount of waste bleaching earth (WBE) is utilised and most of it is disposed at landfills [4].

Oleochemicals are derivatives of fats and oils that are used in the chemical industry to produce several products and these products are then used in numerous applications. Oleochemicals are produced from glycerin, fatty acids, esters, amines, amides, alcohols and other compounds. The competitiveness of the oleochemicals and their opportunities usually lie not only with economics, but also with awareness of environment protection [2].

*For correspondence
Fatty acid esters are widely used as intermediates in oleochemistry. From fatty acid esters, various types of products such as super amides and fatty alcohols, biosurfactants, hydraulic and drilling fluids, and biodegradable polyesters can be synthesised [5]. There are also other industrial applications as lubricants, anti-rust agents and plasticisers. In recent years, fatty acids alkyl esters have come out as potential substitutes of conventional diesel fuel [6-10].

Fatty acid esters are conventionally produced by transesterification of vegetable oils and fats. In these reactions, oil reacts with short-chain alcohols such as methanol or ethanol in the presence of a suitable catalyst [11-15].

Although alkyl esters are produced in volume, their high price limits their applications. Some of these markets purchase raw materials based on price alone, so the lowestquality oils are usually preferred. A successful operation can take the cheapest waste oils and convert them into highvalue end products. A good example of this is the conversion of spent restaurant grease and municipal sewage sludge into biodiesel fuel [16, 17]. Waste vegetable oil from edible oil refining industries is also a suitable substrate for ester production $[16,18]$.

WBE from crude oil refining industries that contains up to $40 \%$ waste oil is also a suitable raw material for alcoholysis reaction [18]. There are several studies on utilisation of WBE. Solvent extraction is the most extensively 
used method for recovery of residual oil from WBE in research studies [4, 19-23]. The other recovery studies are on supercritical $\mathrm{CO}_{2}$ extraction $[4,24,25]$ or lye extraction [26].

Park et al $[16,27]$ studied the utilisation of WBE generated from soybean, rapeseed and palm oils refinery facilities in biodiesel by production by lipase catalysis. They have found the highest conversion yield to be $55 \%$ (w/w) with palm oil after $96 \mathrm{~h}$ of reaction.

In our previous work on utilisation of WBE, response surface methodology was used to optimise the parameters affecting biodiesel production in the presence of $\mathrm{NaOH}$ catalyst. Critical values were determined to be a temperature of $57.3^{\circ} \mathrm{C}$, a catalyst amount of $2.1 \%$ (based on oil weight), and an oil/methanol molar ratio of 1/6.3 [18].

In all the studies on WBE, free fatty acid contents of the extracted oils are high. Those oils are not suitable for food applications. However, it is worthy that it could be converted to valuable products such as alkyl esters [4, 18, 27, 28].

In addition to all these research efforts, there is still no significant research on comparison of catalyst application in waste bleaching earth oil utilisation. The aim of this work is to investigate parameters such as catalyst amount and type, oil:alcohol molar ratio and temperature affecting alcoholysis reaction using WBE. Furthermore, the results were integrated with experimental design and the response surface methodology for discussing the effects of parameters on reaction.

\section{Experimental section}

\subsection{Materials and methods}

WBE was provided from Besler Gida San. Tic. A.S (Istanbul, Turkey). All the other chemicals were of analytical grade and were purchased from Merck Chemical Co. (Darmstadt, Germany).

\subsection{Waste bleaching earth oleochemicals production unit (WBE-OCPU) process and equipment}

Oleochemicals production unit (figure 1) was designed and constructed to produce alkyl esters from waste bleaching earth in the presence of different types of alkali catalysts. The main equipment in the unit is a continuous operating reactor equipped with a cooling jacket for temperature control. The capacity of the reactor is $500 \mathrm{~mL}$. Agitation was controlled by an agitator (Yellowline, IKA Werke $\mathrm{GmbH} \&$ Co. KG Germany). Temperature was controlled by a circulated water bath (Julabo, Germany). At the end of the reaction, ester was recovered using neutralisation and washing steps. The system consists of a solvent tank, an extractor, a reactor for the transesterification reaction and a condenser for solvent recovery.

\subsection{Characterisation of oil}

Waste oil was extracted from WBE via solvent extraction. WBE was mixed with n-hexane at room temperature $\left(25^{\circ} \mathrm{C}\right)$ for $10 \mathrm{~min}$ then the mixture was decanted and oil phase was separated from mixture in n-hexane. The hexane was removed with a rotary evaporator at $70^{\circ} \mathrm{C}$ under vacuum. The oil content of WBE was determined as $27 \%$ (w/w). The characterisation studies of WBE oil were conducted to determine its acid value, saponification value, iodine value, polar material content and density. Then fatty acid methyl esters were prepared by $\mathrm{BF}_{3}-$ methanol reagent esterification according to the AOCS Official Method Ce 2-66. Then the produced esters were analysed by GC-FID using an Agilent 6890 series chromatograph coupled with flame ionised detector and a column (DB-Wax $30 \mathrm{~m}, 0.32 \mathrm{~mm}$ (ID), $0.25 \mu \mathrm{m}$ (film thickness) with a maximum temperature of $250^{\circ} \mathrm{C}$ ). Standard methyl esters of fatty acids were used to determine peak identification of each fatty acid esters by comparing relative retention times. The peak areas were obtained from the computer and the percentages of the fatty acids were calculated as the ratio of the partial area to the total area. Methyl heptadecanoate was used as an internal standard. GC conditions for analysis is that FID temperature $250^{\circ} \mathrm{C}$, injection temperature $250^{\circ} \mathrm{C}$, oven temperature $200^{\circ} \mathrm{C}(12 \mathrm{~min}), 200-230^{\circ} \mathrm{C}\left(5^{\circ} \mathrm{C} / \mathrm{min}\right)$ and $230^{\circ} \mathrm{C}(10 \mathrm{~min})$.

\subsection{Alcoholysis reactions}

The reactions were carried out in the WBE-OCPU system. The stirring rate was adjusted to $600 \mathrm{rpm}$, and the reaction temperature was kept constant with an accuracy of $2^{\circ} \mathrm{C}$ by the temperature controller of circulated water bath. In the present study, methanol or ethanol was used as a reactant.

In the first part, methanol was used as the reactant. First, methanol and catalyst were added to the reactor, waste bleaching earth was added to the extractor simultaneously, then a solvent (in this case, n-hexane) was added to extract the oil, and then the extracted oil is fed to the reactor to initiate the reaction. The reaction temperature was kept constant at $69^{\circ} \mathrm{C}$, which is the boiling point of n-hexane; the stirring rate was fixed at $600 \mathrm{rpm}$. After the reaction, ester phase was recovered using neutralisation and washing steps. To monitor the reactions, samples $(1 \mathrm{~mL})$ were taken at selected time intervals and cooled in an ice-water bath for $15 \mathrm{~min}$ to terminate the reaction.

In the present study, methanol or ethanol was used as a reactant. 


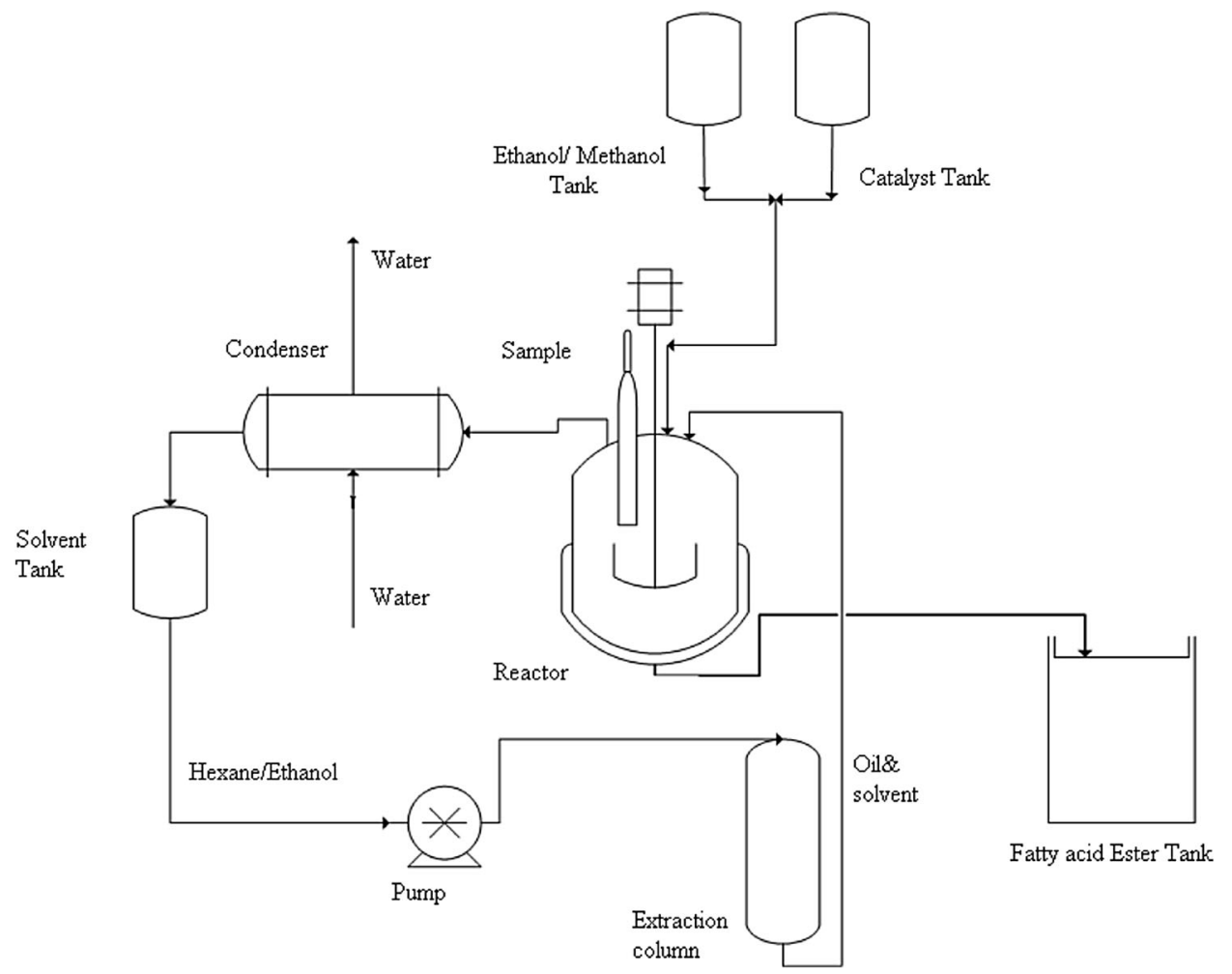

Figure 1. Waste bleaching earth oleochemicals production unit (WBE-OCPU).

In the second part, ethanol was used as the reactant. Since ethanol can be used as solvent for oil, in this case n-hexane was not used. For ethanolysis, first, half part of ethanol and catalyst were added to the reactor, waste bleaching earth was added to the extractor simultaneously, then the other part of ethanol was added to the extractor to extract the oil, and then the extracted oil was fed to the reactor to initiate the reaction. The reaction temperature was kept constant at $78^{\circ} \mathrm{C}$, which is the boiling point of ethanol; the stirring rate was fixed at $600 \mathrm{rpm}$. After the reaction, the ester phase was recovered using neutralisation and washing steps. To monitor the reactions, samples $(1 \mathrm{~mL})$ were taken at selected time intervals and cooled in an ice-water bath for 15 min to terminate the reaction.

The reactions were conducted in the presence of different catalysts such as $\mathrm{NaOH}$, sodium methoxide $\left(\mathrm{NaOCH}_{3}\right)$ and homogeneous alkali polymeric gel catalyst (HAPJEK).

\subsection{Experimental design}

Experimental design and a response surface methodology were conducted to study the effects of the process variables on esterification reaction. The temperature, catalyst amount and oil:alcohol molar ratio was selected as the influence (independent) variables, and the ester content of product (\%) were selected as the dependent variable.

\section{Results and discussion}

\subsection{Characterisation of oil}

The main characteristics and fatty acid compositions of WBE oil are shown in table 1 . According to the fatty acid composition of WBE oil, the calculated mean molecular weight is $889.9 \mathrm{~kg} / \mathrm{kg}-\mathrm{mol}$.

Table 1. The properties of waste bleaching earth oil.

\begin{tabular}{lc}
\hline Property & WBE oil \\
\hline Acid value (mg KOH g) & 20.62 \\
Saponificantion value (mg KOH g) & 190.74 \\
Iodine value (g I 100 g oil) & 62 \\
Polar material (\%) & 4.00 \\
Density (g ml) & 0.9382 \\
Calculated mean molecular weight (kg kmole) & 889.9 \\
\hline
\end{tabular}

Fatty acids contents (\%wt)

\begin{tabular}{|c|c|c|c|}
\hline Miristic acid; C14:0 & 0.15 & Arasitic acid; C20:0 & 0.77 \\
\hline Palmitic acid; C16:0 & 18.40 & $\begin{array}{c}\text { Eicosenoic acid; } \\
\text { C20:1 }\end{array}$ & 3.01 \\
\hline Stearic acid; C18:0 & 8.69 & Behenic acid; C22:0 & 1.86 \\
\hline Oleic acid; C18:1 & 50.13 & Erucic acid; C22:1 & 0.79 \\
\hline Linoleic acid; C18:2 & 14.46 & $\begin{array}{c}\text { Lignoceric acid; } \\
\text { C24:0 }\end{array}$ & 0.27 \\
\hline Linolenic acid; C18:3 & 0.99 & Nervonic acid; C24:1 & 0.47 \\
\hline
\end{tabular}




\subsection{Alcoholysis reactions}

In the studies, the methanolysis and ethanolysis reactions, in which temperature and stirring rate were kept constant in the presence of different catalysts and catalyst amounts (1-2\% based on oil weight), were conducted.

The influence of agitation rate was not very significant. In fact, in transesterification reaction, the reactants initially form a two-phase liquid system. The reaction is diffusioncontrolled and poor diffusion between the phases results in a slow rate. While methyl esters are formed, they act as a mutual solvent for the reactants and a single-phase system is formed. The mixing effect is most significant during the slow rate region of the reaction. As the single phase is established, mixing becomes insignificant $[29,30]$.

In these experiments, $\mathrm{NaOH}$, sodium methoxide $\left(\mathrm{NaOCH}_{3}\right)$ and HAPJEK were used as catalysts. Experimental results of the ester content (\%wt) for ethanolysis and methanolysis are shown in figures 2 and 3, respectively. As shown in the figures, the highest ester contents were obtained in the presence of $2 \% \mathrm{NaOCH}_{3}$ catalyst as $89.4 \%$ in methanolysis and $71.7 \%$ in ethanolysis reaction. Although necessity of solvent usage is a drawback for methanolysis reactions, ester contents obtained in the methanolysis reaction are higher than that in the ethanolysis reaction. This can be explained by the higher solubility of free fatty acids in methanol due to its high polarity.

As can be seen in figures $2 a$ and 3a, the alkyl ester contents were lower with $\mathrm{NaOH}$ catalyst than with the other catalysts. This can be explained by the difficulty in separation of oil phase and glycerin phase because of saponification in the presence of $\mathrm{NaOH}$ catalyst.

As can be seen in figures $2 \mathrm{~b}$ and $3 \mathrm{~b}$, since saponification is lower in the reaction conducted with $\mathrm{NaOCH}_{3}$, higher ester content was obtained than $\mathrm{NaOH}$-catalysed reactions.

HAPJEK was the other catalyst used in the studies. Since water was kept by HAPJEK, reactions were very fast and separation of phases was the easiest among all the catalysts. As a result, ester contents obtained were also higher.

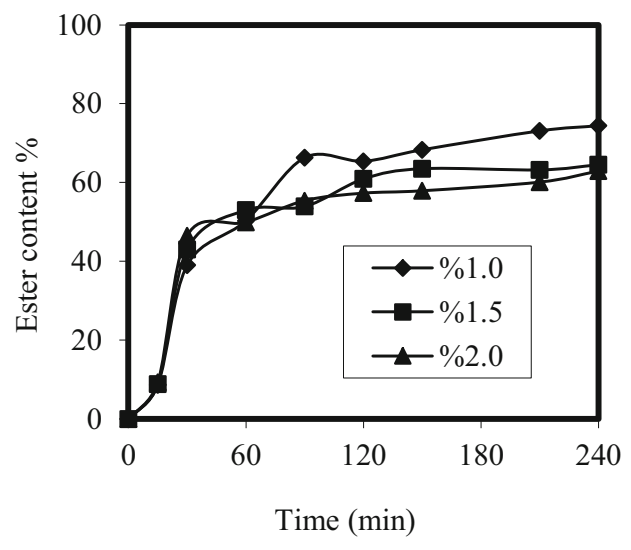

(a)

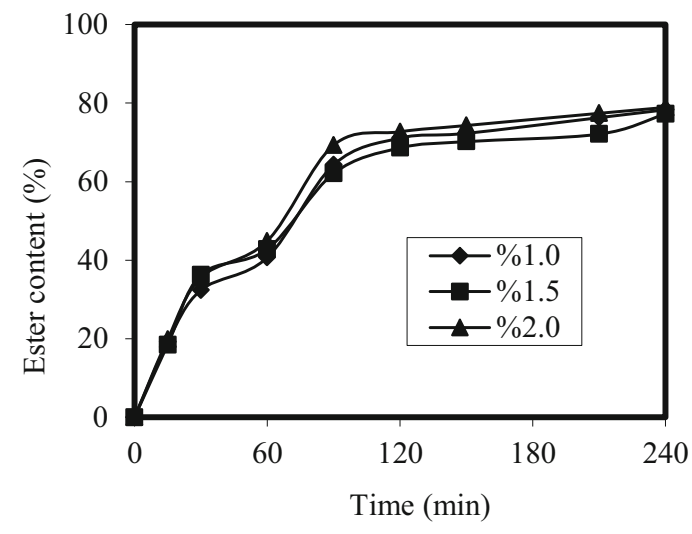

(b)

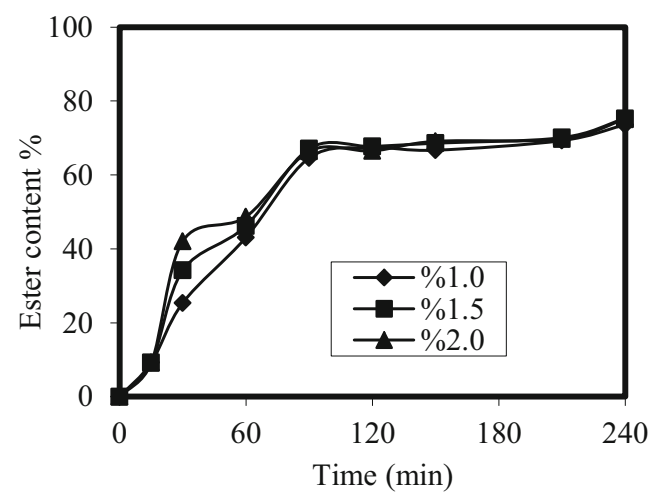

(c)

Figure 2. Ethanolysis reactions in the presence of different cat: oil amount; at $78^{\circ} \mathrm{C}, 600 \mathrm{rpm}$ in the presence of catalyst. (a) $\mathrm{NaOH}$ catalyst. (b) $\mathrm{NaOCH}_{3}$ catalyst. (c) HAPJEK. 


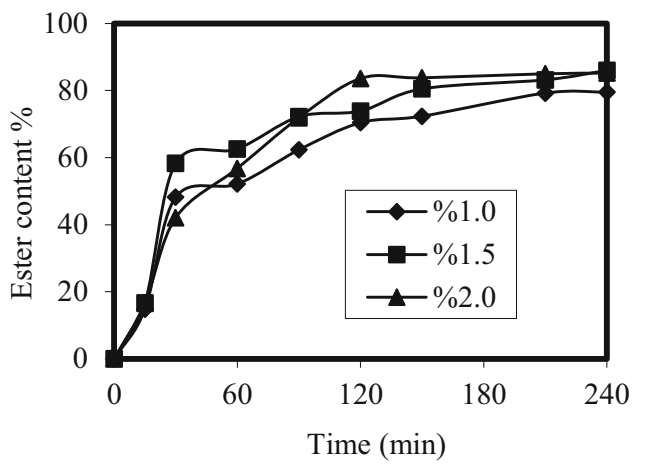

(a)

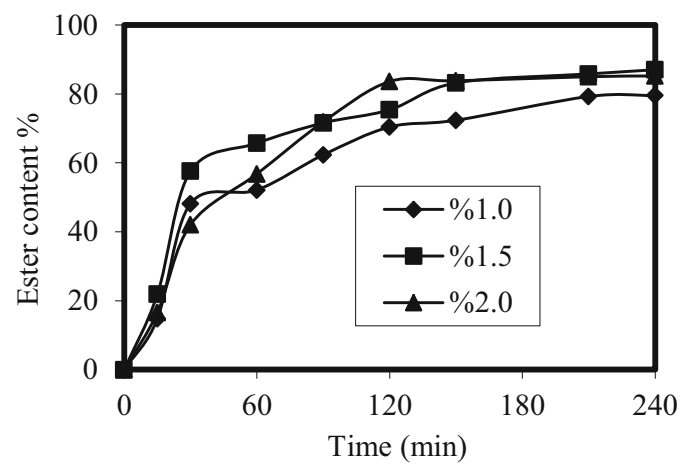

(b)

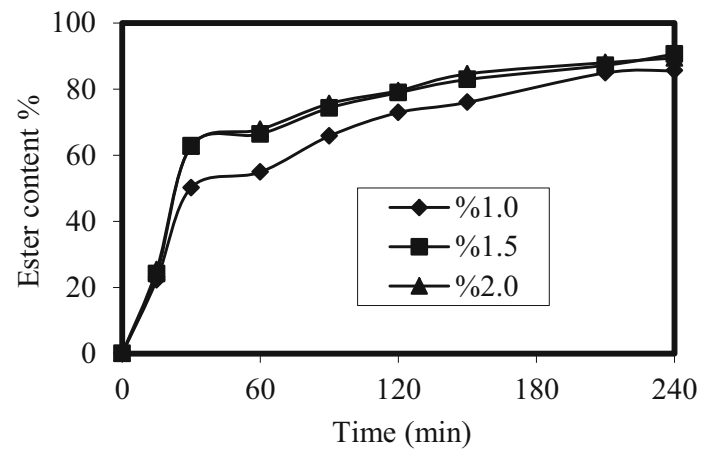

(c)

Figure 3. Methanolysis reactions in the presence of different cat: oil amount; at $69^{\circ} \mathrm{C}, 600 \mathrm{rpm}$ in the presence of catalyst. (a) $\mathrm{NaOH}$ catalyst. (b) $\mathrm{NaOCH}_{3}$ catalyst. (c) HAPJEK.

Table 2. Three-level, three-factor face-centered cubic design and responses for methanolysis.

\begin{tabular}{|c|c|c|c|c|c|c|c|}
\hline & \multicolumn{2}{|c|}{$\mathrm{X} 1$} & \multicolumn{2}{|c|}{$\mathrm{X} 2$} & \multicolumn{2}{|c|}{ X3 } & \multirow{2}{*}{$\begin{array}{l}\text { Ester content }(\% \mathrm{wt}) \\
\text { Value }\end{array}$} \\
\hline & Code & Value & Code & Value & Code & Value & \\
\hline 1 & -1 & 0.01 & -1 & 5 & -1 & 60 & 65.2 \\
\hline 2 & -1 & 0.01 & +1 & 7 & -1 & 60 & 69.3 \\
\hline 3 & +1 & 0.02 & -1 & 5 & -1 & 60 & 69.2 \\
\hline 4 & +1 & 0.02 & +1 & 7 & -1 & 60 & 71.6 \\
\hline 5 & -1 & 0.01 & -1 & 5 & +1 & 70 & 84.4 \\
\hline 6 & -1 & 0.01 & +1 & 7 & +1 & 70 & 89.4 \\
\hline 7 & +1 & 0.02 & -1 & 5 & +1 & 70 & 87.3 \\
\hline 8 & +1 & 0.02 & +1 & 7 & +1 & 70 & 85.9 \\
\hline 9 & 0 & 0.015 & 0 & 6 & -1 & 60 & 71.7 \\
\hline 10 & 0 & 0.015 & 0 & 6 & +1 & 70 & 88.6 \\
\hline 11 & -1 & 0.01 & 0 & 6 & 0 & 65 & 84.6 \\
\hline 12 & +1 & 0.02 & 0 & 6 & 0 & 65 & 87.0 \\
\hline 13 & 0 & 0.015 & -1 & 5 & 0 & 65 & 83.0 \\
\hline 14 & 0 & 0.015 & +1 & 7 & 0 & 65 & 87.0 \\
\hline 15 & 0 & 0.015 & 0 & 6 & 0 & 65 & 86.7 \\
\hline 16 & 0 & 0.015 & 0 & 6 & 0 & 65 & 86.9 \\
\hline 17 & 0 & 0.015 & 0 & 6 & 0 & 65 & 86.2 \\
\hline
\end{tabular}

\subsection{Experimental design}

Higher ester content was obtained in methanolysis than in ethanolysis; therefore, experimental design reactions were continued with methanol. Although ester content was higher for reactions in the presence of HAPJEK, $\mathrm{NaOCH}_{3}$ was selected as the catalyst, because gel formation was encountered in HAPJEK-catalysed reactions. 
Table 3. The results of the analysis of variance (ANOVA).

\begin{tabular}{|c|c|c|c|c|c|}
\hline Factor & Sum of square & Degree of freedom & Mean square & $F$ value & $p$ value \\
\hline Cat amount (L) & 6.561 & 1 & 6.5610 & 9.787 & 0.016645 \\
\hline Cat amount (Q) & 1.652 & 1 & 1.6519 & 2.464 & 0.160455 \\
\hline Mol ratio $(\mathrm{L})$ & 19.881 & 1 & 19.8810 & 29.657 & 0.000960 \\
\hline Mol ratio $(\mathrm{Q})$ & 6.733 & 1 & 6.7327 & 10.043 & 0.015727 \\
\hline Temperature (L) & 784.996 & 1 & 784.9960 & 1171.018 & 0.000000 \\
\hline Temperature (Q) & 110.953 & 1 & 110.9528 & 165.514 & 0.000004 \\
\hline $1 \mathrm{~L} * 2 \mathrm{~L}$ & 8.201 & 1 & 8.2013 & 12.234 & 0.010023 \\
\hline $1 \mathrm{~L} * 3 \mathrm{~L}$ & 5.951 & 1 & 5.9512 & 8.878 & 0.020528 \\
\hline $2 \mathrm{~L} * 3 \mathrm{~L}$ & 1.051 & 1 & 1.0512 & 1.568 & 0.250685 \\
\hline Error & 4.692 & 7 & 0.6704 & & \\
\hline Total SS & 1084.62 & 16 & & $R^{2}=0.97$ & \\
\hline
\end{tabular}

The results of experimental design and response factors are given in table 2 . The quadratic polynomial equation obtained from response surface methodology analysis of the experimental data is listed in the following equation:

$$
\begin{aligned}
Y= & 86.59+0.81 * \mathrm{X} 1-0.79 * \mathrm{X} 1^{2}+1.41 * \mathrm{X} 2 \\
& -1.59 * \mathrm{X} 2^{2}+8.86 * \mathrm{X} 3-5.89 * \mathrm{X} 3^{2}+6.44 * \mathrm{X} 3 \\
& * \mathrm{X} 2-0.86 * \mathrm{X} 3 * \mathrm{X} 1-1.01 * \mathrm{X} 1 * \mathrm{X} 2
\end{aligned}
$$

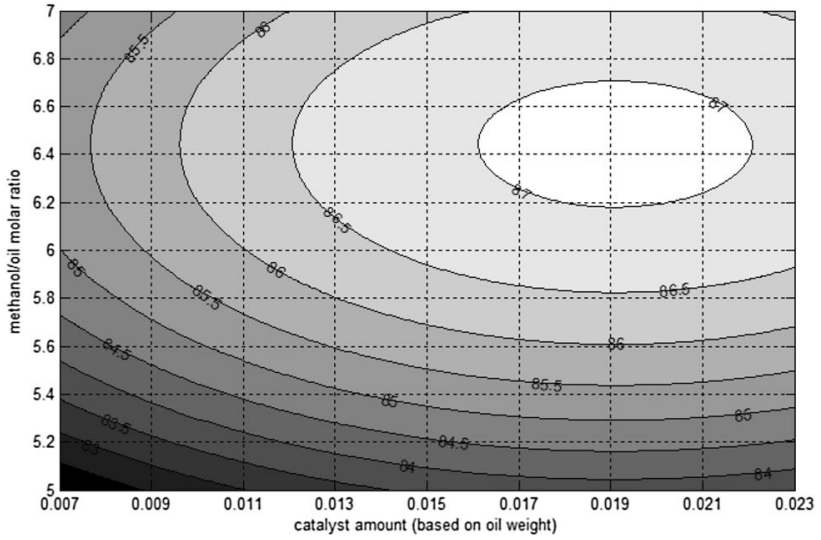

(a)

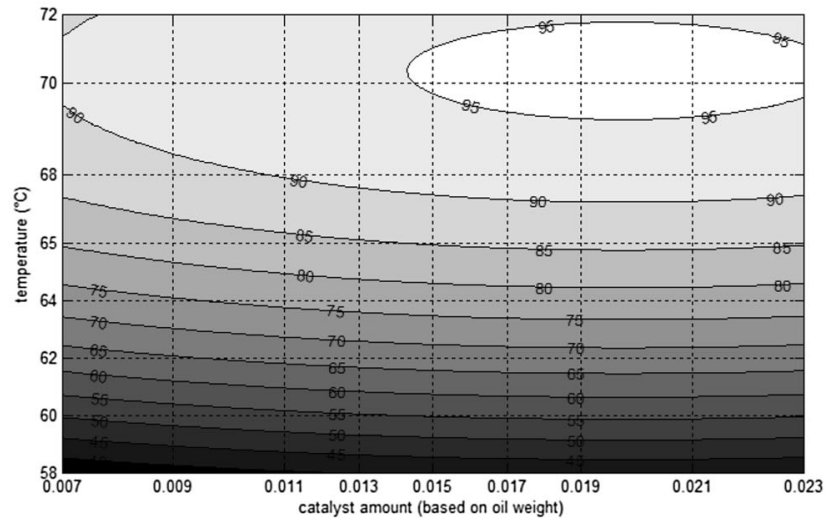

(b)

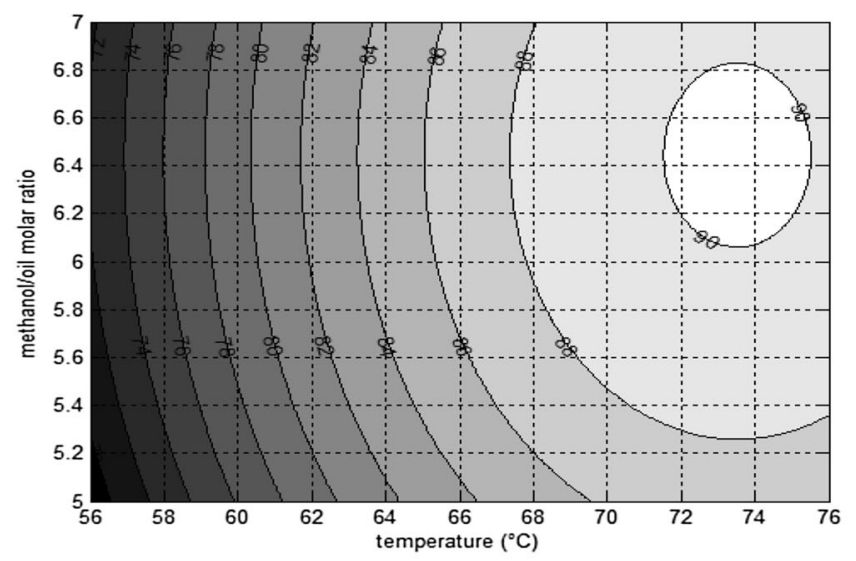

(c)

Figure 4. 2-D contour plot showing the effect of variables on the methyl ester content. (a) Methanol:oil molar ratio vs. catalyst amount. (b) Temperature vs. catalyst amount. (c) Methanol:oil molar ratio vs. temperature. 
where $Y$ is the ester content (\%), and $\mathrm{X} 1, \mathrm{X} 2$ and $\mathrm{X} 3$ are the coded values of independent variables representing catalyst amount, methanol:oil molar ratio and temperature, respectively.

The results of the analysis of variance (ANOVA) for the RSM model are given in table 3 . Since the highest value of $F$ model was obtained from temperature parameter, the most significant parameter can be determined as temperature. The high coefficient of determination $\left(R^{2}=0.97\right)$ indicates that the quadratic regression model approximates $97 \%$ of the real data points. The significance of each regression coefficient is determined by $p$ values. When $p$ value of a corresponding coefficient is smaller, it is more significant.

The relationship between the responses and process parameters were examined by figure 4 . As seen in figure $4 \mathrm{a}$, when the methanol molar ratio was higher than 6.0, the higher ester content was obtained. Higher ester content was obtained with increasing catalyst plots regarding the effect of catalyst amount, temperature and their interactions on the methyl ester content. It can be seen in figure $4 \mathrm{~b}$ that the temperature effect is very high on reaction. When the temperature was higher than $64^{\circ} \mathrm{C}$, higher ester content was obtained. Contour plots in figure $4 \mathrm{c}$ show the effects of the methanol:oil molar ratio, temperature, and their interactions on the methyl ester content. The methyl ester content could reach values over $80 \%$ when the substrate molar ratio was between 5.6 and 6.4 at $64^{\circ} \mathrm{C}$.

The critical values for 210 min reaction time with a maximum $85.8 \%$ methyl ester content were determined on the conditions of temperature: $68.4^{\circ} \mathrm{C}$, catalyst amount (oil weight based): $1.5 \%$ and methanol/oil molar ratio: 6.4 . This result was also confirmed by the reaction conducted under optimum conditions.

\section{Conclusion}

Waste bleaching earth (WBE) can be utilised in oleochemical production. The study results reveal that WBE oil can be recoverable and suitable for alcoholysis. Although necessity of solvent usage was a drawback of methanolysis reactions, higher ester contents were obtained in the methanolysis reaction than that in the ethanolysis reaction. This can be explained by better solubility of free fatty acids in methanol due to its high polarity. The highest ester content was obtained in the presence of HAPJEK and $\mathrm{NaOCH}_{3}$. Moreover, oil/glycerine phase separation was observed to be easier. The relationship between variables and ester content can be explained by an empirical model derived from RSM in oleochemical production via alcoholysis.

\section{Acknowledgements}

The fuel characterisation infrastructure and experimental set-up used in this study was constructed in TUBITAK
MRC within the project "Alternative Motor Fuel: Biodiesel" founded by state planning organisation.

\section{References}

[1] Isler A, Sundu S, Tuter M and Karaosmanoğlu F 2010 Transesterification reaction of the fat originated from solid waste of the leather industry. J. Waste Manag. 30: 2631-2635

[2] Shahidi F and Bailey A E 2005 Bailey's industrial oil and fat products. Wiley, New York, Chichester

[3] Karmperis A C, Aravossis K, Tatsiopoulos I P and Sotirchos A 2013 Decision support models for solid waste management: review and game-theoretic approaches. J. Waste Manag. 33: 1290-1301

[4] Kheang L S, Foon C S, May C Y and Ngan M A 2006 A study of residual oils recovered from spent bleaching earth: their characteristics and applications. Am. J. Appl. Sci. 3: 2063-2067

[5] Mittelbach M 1990 Lipase catalyzed alcoholysis of sunflower oil. J. Am. Oil Chem. Soc. 61: 168-70

[6] Lara P V and Park E Y 2004 Potential application of waste activated bleaching earth on the production of fatty acid alkyl esters using Candida cylindracea lipase in organic solvent system. Enzyme Microb. Technol. 34: 270-277

[7] Alptekin E, Canakci M and Sanli H 2014 Biodiesel production from vegetable oil and waste animal fats in a pilot plant. J. Waste Manag. 34: 2146-2154

[8] Ozgunay H, Colak S, Zengin G, Sarı O, Sarıkahya H and Yüceer L 2007 Performance and emission study of biodiesel from leather industry prefleshings. J. Waste Manag. 27: 1897-1901

[9] Felizardo P, NeivaCorreia M J, Raposo I, Mendes J F, Berkemeier R and Bordado J M 2006 Production of biodiesel from waste frying oils. J. Waste Manag. 26: 487-494

[10] Charpe T W and Rathod V K 2011 Biodiesel production using waste frying oil. J. Waste Manag. 31: 85-90

[11] Prateepchaikul G, Somnuk K and Allen M 2009 Design and testing of continuous acid-catalyzed esterification reactor for high free fatty acid mixed crude palm oil. Fuel Process. Technol. 90: 784-789

[12] Reyero I, Arzamendi G and Zabala L M 2015 Kinetics of the $\mathrm{NaOH}$-catalyzed transesterification of sunflower oil with ethanol to produce biodiesel. Fuel Process. Technol. 129: 147-155

[13] Torres E A, Cerqueira G S, Ferrer T M, Quintella C M, Raboni M, Torretta V and Urbini G 2013 Recovery of different waste vegetable oils for biodiesel production: a pilot experience in Bahia State, Brazil. J. Waste Manag. 33: 2670-2674

[14] Ghosh P K 2010 Process for the preparation of fatty acid methyl ester from triglyceride oil by transesterification. US $7,666,234$ B2

[15] Ghosh P K 2010 Integrated process for the production of jatropha methyl ester and by products. EP 2475754 B1

[16] Park E Y and Pizarro L 2003 Lipase catalyzed production of biodiesel fuel from vegetable oils contained in waste activated bleaching earth. Process Biochem. 38: 1077-1082 
[17] Olkiewicz M, Caporgno M P, Fortuny A, Stüber F, Fabregat A, Font J and Bengoa C 2014 Direct liquid-liquid extraction of lipid from municipal sewage sludge for biodiesel production. Fuel Process. Technol. 128: 331-338

[18] Gül Ö F, Tüter M and Aksoy H A 2010 The utilization of waste activated bleaching earth in biodiesel production: optimization by response surface methodology. Energy Sources A: Recovery, Utiliz. Environ. Effects 32: 1812-1820

[19] Ong J T L 1983 Oil recovery from spent bleaching earth and disposal of the extracted material. J. Am. Oil Chem. Soc. 60: 314-315

[20] Kalam A and Joshi J 1988 Regeneration of spent earth by wet oxidation. J. Am. Oil Chem. Soc. 65: 1536

[21] Aziz A R, Harcharan S, Elkanzi E M, Lam L S and Liew S H 2001 Feasibility study of oil recovery from used bleaching earth using waste solvents. Porim Intl. Palm Oil Cong. (PIPOC) Proc., 126-133

[22] Yoo C K and Lin S W 2004 Regeneration of spent bleaching clay. Malaysian Palm Oil Board TT, 230

[23] Huang Y P and Chang J I 2010 Biodiesel production from residual oils recovered from spent bleaching earth. Renew. Energy 35: 269-275
[24] Waldmann C and Eggers R 1991 De-oiling contaminated bleaching clay by high-pressure extraction. J. Am. Oil Chem. Soc. 68: 922-930

[25] King J W, List G R and Johnson J H 1992 Supercritical carbon dioxide extraction of spent bleaching clays. J. Super Crit. Fluids 5: 38-41

[26] Chang J I, Tai H S and Huang T H 2006 Regeneration of spent bleaching earth by lye extraction. Environ Prog. 25: 373-378

[27] Park E, Sato M and Kojima S 2008 Lipase-catalyzed biodiesel production from waste activated bleaching earth as raw material in a pilot plant. Bioresource Technol. 99: 3130-3135

[28] Škrbić B, Predojević Z and Đurišić-Mladenović N 2015 Esterification of sludge palm oil as a pretreatment step for biodiesel production. Waste Manag. Res. 33(8): 723-729

[29] Vicente G, Martínez M, Aracil J and Esteban A 2005 Kinetics of sunflower oil methanolysis. Ind. Eng. Chem. Res. 44: 5447-5454

[30] Rashid U, Anwar F, Yunus R H and Al-Muhtaseb A 2015 Transesterification for biodiesel production using Thespesia populnea seed oil: an optimization study. Int. J. Green Energy 12(5): 479-484 